Revista Destaques Acadêmicos, Lajeado, v. 11, n. 3, 2019. ISSN 2176-3070

DOI: http://dx.doi.org/10.22410/issn.2176-3070.v11i3a2019.2238

http://www.univates.br/revistas

\title{
ANÁLISE MICROBIOLÓGICA DE MAMADEIRAS EM ESCOLAS DE EDUCAÇÃO INFANTIL: IDENTIFICAÇÃO E ESTUDO DE TÉCNICAS DE DESINFECÇÃO
}

\author{
Natália de Oliveira Flores ${ }^{1}$, Jairo Luis Hoerlle ${ }^{2}$, \\ Gabriela Kniphoff da Silva Lawisch ${ }^{3}$, Mônica Jachetti Maciel ${ }^{4}$
}

\begin{abstract}
Resumo: As mamadeiras, apesar de serem importantes e fornecerem uma praticidade aos pais e cuidadores, são objetos de fácil contaminação. A manipulação por diversas pessoas e a não desinfecção correta podem expor a criança a inúmeros microrganismos patogênicos. $\mathrm{O}$ objetivo deste trabalho foi a realização de analise microbiológica de mamadeiras em escolas de educação infantil, com respectiva identificação dos possíveis microrganismos encontrados e estudo da eficácia de três técnicas de desinfecção, sendo elas a técnica com hipoclorito de sódio, a técnica de fervura e o teste com vinagre de álcool. As mamadeiras foram escolhidas aleatoriamente, e a identificação microbiológica foi realizada conforme Manual da Agência Nacional de Vigilância Sanitária. Foram testadas, em triplicatas, três técnicas de desinfecção, sendo elas as técnicas com hipoclorito de sódio, a técnica de fervura, e a utilização de vinagre de álcool. De trinta amostras, oito apresentaram crescimento bacteriano, sendo identificados os seguintes microrganismos: Staphylçococcus spp., coagulase negativa, em duas amostras da escola municipal, Klebsiella pneumonie e Escherichia coli em seis amostras coletadas na escola da rede particular. A técnica de fervura se mostrou mais eficaz na desinfecção das cepas testadas. Os resultados mostraram que existem falhas nos processos de limpeza e desinfecção das escolas, visto que houve crescimento de bactérias patogênicas. Ressaltase a importância de revisão das técnicas de desinfecção com os responsáveis, visando garantir melhores condições higiênico-sanitárias nestes ambientes.
\end{abstract}

Palavras-chave: Mamadeiras. Escola. Desinfecção. Microbiologia.

1 Biomédica pela Universidade do Vale do Taquari - Univates.

2 Mestre em Medicina pela UFRGS, coordenador do Laboratório de Análises Clínicas Univates.

3 Mestre em Genética e Biologia Molecular pela UFRGS, professora da Univates.

4 Professora e Pesquisadora do Centro de Ciências Biológicas e da Saúde (CCBS) e do Programa de Pós-Graduação em Sistemas Ambientais Sustentáveis (PPGSAS) 


\section{INTRODUÇÃO}

As escolas de educação infantil, geralmente são o primeiro ambiente em comunidade onde a criança convive, sendo também, o primeiro local de exposição a agentes contaminantes (GURGEL et al., 2005). Em razão disso, as boas práticas de manuseio e limpeza dos alimentos e objetos que irão entrar em contato com a criança, principalmente pela via oral, são de suma importância na prevenção de contaminação e exposição das crianças a patógenos (ACCIOLY; SANDERS; LACERDA, 2009). Estes ambientes são considerados o $5^{\circ}$ local de maior incidência de surtos alimentares notificados no país, totalizando $8,6 \%$ dos casos (BRASIL, 2018).

As cozinhas das escolas são os locais de preparado dos alimentos e higienização das mamadeiras, que devem ser limpas, preparadas, desinfectadas e distribuídas (BRASIL, 2005; FERREIRA; COSTA 2001). Esses ambientes objetivam garantir a oferta de alimentos seguros e adequados do ponto de vista microbiológico e nutricional, sob a responsabilidade de um profissional devidamente capacitado e com auxílio de equipamentos de limpeza, desinfecção e armazenamento adequados (GALEGO et al., 2017; BRASIL, 2005).

As doenças de transmissão hídrica e alimentar (DTHA), causadas por ingesta de alimentos e bebidas contaminadas por agentes infecciosos ou toxinas, são a causa de inúmeros surtos pelo país, sendo a região Sul a segunda no ranking dos anos de 2000 a 2017 (BRASIL, 2018). A transmissão de tais patologias é amplamente relacionada aos manipuladores, seus descuidos e falta de higienização correta de utensílios e dos próprios alimentos (ANDRADE; MACEDO,1996; CARDOSO et al., 1996; OLIVEIRA, 2003). Dentre os principais objetos usados dentro do ambiente escolar de crianças, destaca-se a mamadeira (BUCCINI; BENICIO; VENANCIO, 2014). O principal alimento ofertado na mamadeira é o leite, sendo este um meio favorável de crescimento bacteriano, que sofre alterações em curtos espaços de tempo.

O tempo entre a manipulação e a distribuição da mamadeira, e a higiene dos dois processos são fundamentais na transmissão de possíveis doenças. Devido à imaturidade gastrointestinal e imunológica, as crianças são mais suscetíveis à diversas patologias, sendo importante oferecer condições higiênico-sanitárias adequadas e alimentos devidamente descontaminados a elas (BRASIL, 2006; ACCIOLY; SANDERS; LACERDA, 2009). O processo de desinfecção pode ser realizado por vários métodos, físicos e químicos. Porém, a estrutura física das escolas não permite a execução de alguns procedimentos, então, as recomendações para a desinfecção envolvem hipoclorito de sódio, como método químico e a fervura da água como método físico, ambas orientadas pela legislação vigente. Existem algumas restrições quanto ao uso de hipoclorito e seu risco residual nas mamadeiras, uma alternativa a este método seria o uso de vinagre de álcool, um sanitizante que destrói ou reduz o número de microrganismos patogênicos (GRANADA et al., 2000; NASCIMENTO et al., 2003). 
As técnicas de limpeza e desinfecção devem ser realizadas de forma correta e eficaz. A conscientização dos manipuladores de objetos e alimentos de lactários educacionais sobre a importância desses processos é a principal maneira de evitar contaminações e surtos. Oliveira, Brasil e Taddei (2008) citam que os manipuladores são os principais causadores de contaminação, devido a descuidos e falta de treinamento adequado. Para orientar e padronizar as técnicas que devem ser utilizadas pelas escolas de educação infantil, existe a Resolução RDC n' 216 de 2004, que estabelece os procedimentos de "Boas Práticas para serviços de alimentação", buscando oferecer alimentos com condições adequadas para consumo nesses locais (BRASIL, 2004).

Estudos demonstram que as crianças que frequentam creches ou instituições similares, adoecem mais do que as que permanecem em casa até os 24 meses (FISBERG; MARCHIONI; CARDOSO, 2004). Os lactentes e menores de quatro anos são mais suscetíveis, pois não possuem imunidade, devido à falta de exposição anterior (SIVIEIRO et al.,1997; CORRÊA et al.,1999). Segundo trabalho publicado por Scherma et al. (2004) as mamadeiras e chupetas são possíveis fatores de risco em caso de Candida em cavidade oral. A introdução de outros alimentos e a falta de higiene bucal, de chupetas e mamadeiras também foram considerados fatores relevantes nos casos estudados. Holmstrup e Samaranayake (1990) e Hoppe (1997) também descrevem as mamadeiras e chupetas como transmissores de Candida.

Com base nestes conhecimentos, este trabalho objetiva a identificação de microrganismos presentes em amostras de mamadeiras de creches, possibilitando conhecer a qualidade higiênico-sanitária destes locais. Ainda, o trabalho consistiu também no estudo das técnicas de desinfecção, química e física, comparando a eficácia destas na diminuição de microrganismos, e avaliando qual apresentará melhor ação.

\section{MATERIAL E MÉTODOS}

Os dados foram obtidos a partir das análises de mamadeiras pertencentes aos alunos das redes municipal e rede particular de ensino. A secretaria municipal de educação, com as escolas, foi informada sobre a pesquisa por meio de ofícios assinados pelos pesquisadores e concordaram com a realização do estudo, cedendo as amostras que foram analisadas. As mamadeiras foram escolhidas de forma aleatória, todas pertencentes às turmas de berçário das escolas, portanto, a crianças com idade inferior a dois anos, totalizando dez amostras, sendo cinco amostras de cada escola.

As coletas foram feitas diretamente nas escolas, após a rotina de limpeza realizada normalmente na escola, com a utilização de swabs estéreis, transportados em meio Stuart até o laboratório de microbiologia. As áreas escolhidas foram: bico, parte interna e externa; fissuras da rosca e parte interna do corpo, em todo seu comprimento e fundo. Para evitar possíveis contaminações 
das amostras durante o processo de coleta, o coletador responsável fez uso de jaleco, luvas e máscara. Os swabs foram identificados conforme a parte da mamadeira, número da amostra e escola de origem. Estas foram analisadas no setor de microbiologia de um laboratório de análises clínicas do mesmo município das escolas.

Os meios de cultivos utilizados foram ágar sangue e ágar MacConkey, em biplacas de cultivo e mantidas em estufa bacteriológica a $36^{\circ}$ graus por 48 horas, e posteriormente, identificadas com base nas características das colônias e auxilio de testes bioquímicos, conforme o Manual da Agência Nacional de Vigilância Sanitária (BRASIL, 2013).

Após a identificação, foram realizados os testes das técnicas de desinfecção, de acordo com as bactérias previamente identificadas nas amostras das mamadeiras. Foram testadas, em triplicatas, três técnicas de eficiência, sendo elas as técnicas com hipoclorito de sódio (orientada pela RDC 216 de 2004), a técnica de fervura (descrita pela portaria $\left.n^{\circ} 172 / 2005\right)$, e o experimento com o vinagre de álcool. Paras essas análises, utilizaram-se objetos testes, que foram contaminados com as bactérias: Klebsiella spp. e Escherichia coli, em concentrações equivalentes a escala 0,5 de Mac Farland. Esses objetos foram imersos em suspensões com inóculos de cada bactéria e após, submetidos, separadamente, a cada técnica do estudo.

O hipoclorito foi utilizado conforme sua orientação para desinfecção de frutas e verduras, mesma concentração que deve ser usada nas escolas nos processos de limpeza e desinfecção das mamadeiras e suas respectivas partes. Conforme orientação do fabricante, foi utilizada a concentração de $10 \%$ por 10 minutos. A técnica de fervura foi feita seguindo as orientações sobre temperatura e tempo que os estabelecimentos de educação infantil devem seguir na rotina de lavagem e desinfecção de mamadeiras. Onde os objetos devem permanecer em água recém fervida por 15 minutos. $\mathrm{O}$ vinagre de álcool foi testado com a concentração de $25 \%$, conforme indicação que consta no trabalho de Fontana (2006), na sanitização de folhas de alface. Após cada procedimento, foi feito a semeadura em biplacas de ágar sangue e ágar MacConkey e incubadas por 24 horas, para verificação de crescimento bacteriano.

\section{RESULTADOS}

As dez amostras foram escolhidas aleatoriamente em cada escola, sendo elas de modelos, marcas e formatos diferentes. As amostras foram separadas por escola e parte em que foi coletado o swab. As escolas possuem rotinas de lavagem e desinfecção orientadas pela vigilância sanitária do município, seguindo orientação da RDC 216 de 2014 da ANVISA, e da portaria n ${ }^{\circ}$ 172/2005 do Centro Estadual de Vigilância em Saúde (CEVS) do Rio Grande do Sul. As duas escolas relataram utilizarem a técnica com hipoclorito de sódio. 
$\mathrm{Na}$ escola de educação infantil foram semeadas 15 biplacas, cinco pertencentes a cada parte da mamadeira: bico, rosca e corpo. As partes são totalmente separadas para a limpeza e desinfecção. Após 24 horas, apenas em duas placas houve crescimento bacteriano, na amostra três, coletada na rosca e na amostra quatro pertencente ao bico da mamadeira. Nas duas amostras, foram identificados Staphylococcus spp., coagulase negativo, em um tempo total de 48 horas de incubação.

As amostras obtidas da escola de educação pertencente à rede particular foram coletadas também após a limpeza, mas as mamadeiras não estavam separadas em suas partes: bico, rosca e corpo. Nessa escola, as mamadeiras apresentavam colônias macroscópicas de fungos na rosca interna, outras aparentavam estarem em uso a bastante tempo, com o corpo de cor opaca e desgastado. O número de swabs coletados foram os mesmos da escola municipal, seguindo-se a mesma regra de identificação das placas e tempo de incubação. Após o período de incubação, algumas amostras apresentaram crescimento microbiano, conforme demonstrado na Tabela 1.

Tabela 1- Identificação bacteriana das amostras pertencentes a escolas da rede particular

\begin{tabular}{c|c|c|c}
\hline $\begin{array}{c}\text { Número da } \\
\text { amostra }\end{array}$ & $\begin{array}{c}\text { Parte da } \\
\text { mamadeira }\end{array}$ & Identificação bacteriana & $\begin{array}{c}\text { Escola de origem da } \\
\text { amostra }\end{array}$ \\
\hline 3 & Corpo & Klebsiella pneumoniae & Escola particular \\
\hline 1 & Rosca & Klebsiella pneumoniae & Escola pública \\
\hline 5 & Rosca & Escherichia coli & \\
\hline 3 & Rosca & Klebsiella pneumoniae & \\
\hline 3 & Rosca & $\begin{array}{c}\text { Staphylococcus spp. (coagulase } \\
\text { negativa) }\end{array}$ & $\begin{array}{c}\text { Staphylococcus spp. (coagulase } \\
\text { negativa) }\end{array}$ \\
\hline
\end{tabular}

Fonte: Do autor.

As técnicas de desinfecção foram realizadas conforme as orientações da ANVISA e CEVS para lactários de estabelecimentos de educação infantil, nos processos de limpeza de mamadeiras, utensílios e alimentos (BRASIL, 2014; BRASIL, 2005). As duas escolas utilizam a técnica com hipoclorito de sódio, na qual as mamadeiras, após serem lavadas com sabão neutro e enxaguadas em água corrente devem ser imersas em solução clorada de até 220 ppm, ou uma colher de sopa para cada um litro de água, e por tempo determinado conforme o fabricante do produto, seguindo as mesmas orientações para desinfecção de frutas e hortaliças. Após o tempo determinado as mamadeiras devem ser 
enxaguadas com água corrente e permanecem em recipientes exclusivos e em ambientes refrigerados até o próximo uso.

Tabela 2- Ação de técnicas de desinfecção frente às cepas de Klebsiella spp. e Escherichia coli

\begin{tabular}{c|c|c}
\hline Técnica de desinfecção & Bactéria & Ação \\
\hline \multirow{2}{*}{ Hipoclorito de sódio (ANVISA) } & Klebsiella spp. & Eficaz \\
\cline { 2 - 3 } & Escherichia coli & Ineficaz \\
\hline \multirow{2}{*}{ Fervura (CEVS) } & Klebsiella spp. & Eficaz \\
\cline { 2 - 3 } & Escherichia coli & Eficaz \\
\hline \multirow{2}{*}{ Vinagre de álcool 25\% } & Klebsiella spp. & Eficaz \\
\cline { 2 - 3 } & Escherichia coli & Ineficaz \\
\hline
\end{tabular}

Fonte: Do autor

\section{DISCUSSÃO}

Os resultados apresentados mostraram que existe uma real exposição das crianças a microrganismos patogênicos, pelo menos em uma das escolas de educação infantil. Andrade e Macedo (1996) citam que surtos de patologias de origem alimentar podem ser originados pelo uso de utensílios sem a devida higienização. A contaminação também pode estar relacionada com descuidos dos manipuladores de alimentos e seus hábitos de higiene pessoal, ou ainda, prática de técnicas ineficazes de limpeza e desinfecção de utensílios usados no preparo e oferta dos alimentos (CARDOSO et al., 1996; OLIVEIRA, 2003).

Os ambientes escolares infantis são, comprovadamente, locais com potencial de propagação de doenças, pela presença de maior número de crianças nos ambientes, o que causa uma maior variedade de microrganismos (AMORIM; ROSSETTI-FERREIRA, 1999). Dessa forma, os manipuladores e demais funcionários possuem papel fundamental na manutenção da limpeza e desinfecção desses locais, visando a oferta de um ambiente limpo e livre de possíveis contaminantes as crianças.

A Escherichia coli é um microrganismo gram-negativo, anaeróbico facultativo, pertencente a microbiota do intestino em suas condições normais, porém, possui característica de se tornar patógeno em condições onde seu hospedeiro se torna suscetível (SOUSA, 2006). Ela pode se espalhar pelo organismo, e já foi relacionado com infecções gastrointestinais, meningites e doenças diarreicas graves (NATARO; KAPER, 1998). A presença de E. coli nas amostras confirma que as mamadeiras, quando usadas com frequência e sem a devida higienização, são locais de fácil proliferação e crescimento bacteriano. O leite, principal alimento ofertado nelas, é um meio de cultivo favorável para o crescimento microbiano e possui facilidade em sofrer alterações em curtos 
períodos de tempo. A água utilizada na reconstituição de fórmulas, em chás, sucos e ofertada pura, também é fonte de coliformes totais e coliformes de origem fecal, em estudo realizado por Sales e Goulart (1997).

A pesquisa também identificou a bactéria Klebsiella pneumonie, um microrganismo gram-negativo, oportunista, pertencente ao grupo de enterobactérias (NOGUEIRA et al., 2009). Está presente nas plantas, no solo, nas águas superficiais e no intestino humano e de outros animais (PODSCHUN et al., 2001). Essa bactéria possui característica de ser oportunista e com capacidade de sobrevivência durante períodos longos, tanto na pele humana, quanto em superfícies secas (CHAPMAN, 1946; JONES, 2010; SCAPARE et al., 2009; PERNA et al., 2015). A Klebsiella é citada como responsável por infecções do trato urinário, pneumonias entre outras, em crianças, idosos e imunodeprimidos (BRISSE et al., 2009). Apesar de ser comumente encontrada em infecções hospitalares, Paczosa e colaboradores (2016), relatam que a Klebsiella também foi responsável por alguns casos em ambiente extra-hospitalar.

Para que as crianças são sejam expostas a microrganismos patógenos, existem protocolos orientados pela legislação e que as escolas de educação infantil devem seguir, como a técnica de hipoclorito de sódio e a fervura. Eles visam padronizar as técnicas de limpeza e desinfecção de todos os objetos e utensílios usados na oferta de alimentos às crianças desses locais (BRASIL, 2016; BRASIL, 2004).

O hipoclorito de sódio age nas funções metabólicas bacterianas, promovendo oxidações em seus sistemas, por meio de reações químicas, resultando em seu efeito antimicrobiano (SIQUEIRA JUNIOR et al., 1998). A diluição de forma incorreta do produto pode permitir que microrganismos não sejam totalmente eliminados, ou então, que a solução se torne tóxica (SILVA JUNIOR, 2012). Neste estudo, essa técnica não se mostrou eficaz perante a bactéria Klebsiella spp. Por ser um microrganismo patogênico e estar presente neste ambiente, destaca-se a importância de uma adequação das técnicas utilizadas para a limpeza desses objetos, propondo uma alternativa eficiente na desinfecção, reduzindo o risco de contaminações entre crianças, manipuladores, demais profissionais da escola e familiares.

Apesar do hipoclorito não ser indicado pelo Ministério da Saúde, ele é utilizado seguindo orientações da CEVS, órgão responsável pela vigilância sanitário (BRASIL, 2005). Além disso, seu uso em materiais plásticos pode causar desgaste do objeto e rachaduras, o que reforça a não indicação, devido ao risco de acúmulo de resíduos nas rachaduras, e consequente contaminação do alimento. Esta exposição ao hipoclorito, pelo resíduo nas rachaduras ou criação de biofilme microbiano, pode causar transtornos gastrointestinais nas crianças expostas a estes objetos (BRASIL,1994; BRASIL,1988; GENELAC, 2013). Produtos com cloro ativo também podem apresentar riscos à saúde quando utilizados na desinfecção de objetos e alimentos. Seu poder de reação com outras substâncias da água pode formar compostos perigosos ao organismo, 
como os radicais livres, que agem em diversos locais e podem causar sérios danos ao corpo (ARTES et al., 2009).

Uma alternativa de baixo custo consiste na utilização do vinagre de álcool. Seu potencial sanitizante possui significativos resultados no combate ao crescimento microbiano, em diversas concentrações. Fontana (2006) verificou que o vinagre de maçã se mostrou eficiente na inibição de crescimento bacteriano, sendo utilizado na concentração de $12,5 \%$, sendo a menor concentração, quando comparada aos outros vinagres utilizados na pesquisa, que objetivava conhecer a atividade antimicrobiana de desinfetantes utilizados na sanitização de alface. A pesquisa utilizou a concentração de $25 \%$, por se tratar de um material (mamadeira) que entra em contato com diversos líquidos e potenciais meios de proliferação bacteriana. Essa técnica se mostrou eficiente frente à Klebsiella spp., se tornando uma alternativa no combate a contaminação por essa bactéria. $\mathrm{O}$ fator que dificultaria seu uso seria a característica olfativa e risco do dor permanecer no objeto após a secagem.

A técnica que demostrou melhor resultado na desinfecção foi a técnica de fervura. Esta técnica, padronizada pela ANVISA, é de menor custo e melhor efetividade, inclusive sugerido por Salles e Goulart (1997) como método a ser utilizado em lactários hospitalares e escolares.

Considerando a importância dos manipuladores dos objetos e alimentos em escolas de educação infantil, visto que os mesmos são citados como uma das principais fontes de contaminação, ressalta-se a importância da capacitação desses indivíduos, em relação aos seus hábitos de higiene pessoal ou uso de técnicas de limpeza e desinfecção dos materiais utilizados para preparo de refeições (CARDOSO et al., 1996; OLIVEIRA, 2003; TRINDADE, 2006). Esses indivíduos, mesmo que não possuam alguma patologia, podem ser fontes de contaminação, pois suas mãos e roupas entram em contato com outros locais, podendo atuar como vetores, fator que pode ser determinante em um quadro de infecção por microrganismos patogênicos (FRANCO; LEDGRAF, 2002).

A realização de análises microbiológicas de forma periódica poderia ser uma ferramenta de controle de contaminação, garantindo assim, melhores condições higiênico-sanitárias para as crianças e suas famílias.

\section{CONCLUSÃO}

Os resultados sugerem que as técnicas utilizadas na limpeza e desinfecção das mamadeiras de uma das escolas não estão sendo executadas corretamente, expondo assim, as crianças a possíveis contaminações. Uma nova capacitação dos manipuladores e uma revisão dos procedimentos de limpeza e desinfecção, pelos órgãos responsáveis, garantiria uma melhor qualidade dos serviços prestados por estes estabelecimentos de educação infantil. O estudo concluiu que a melhor técnica de desinfecção é a fervura. 


\section{REFERÊNCIAS}

ACCIOLY, E.; SAUNDERS, C.; LACERDA, E. M. A. Nutrição em obstetrícia e pediatria. Rio de Janeiro: Guanabara Koogan, 2009.

AMORIM, K. S; ROSSETI - FERREIRA, M. C. Análise crítica de investigações sobre doenças infecciosas respiratórias em crianças que frequentam creche. Jornal de Pediatria, v. 75, n. 5, p. 313-319, 1999.

ANDRADE N. J; MACEDO J. A. B. Higienização na indústria de alimentos. São Paulo, Varela, 1996.

BRASIL. Ministério da Saúde. Agencia Nacional de Vigilância Sanitária - ANVISA. Microbiologia clínica para controle de infecção relacionada a assistência à saúde. Módulo 6: Detecção e Identificação de Bactérias de Importância Medica, 2013.

BRASIL. Ministério da Saúde. Agência Nacional de Vigilância Sanitária. Resolução RDC N 216 de 15 de setembro de 2004. Regulamento Técnico de Boas Práticas para Serviços de Alimentação. Brasília, 2004.

BRASIL. Ministério da Saúde. Coordenação de controle de Infecção Hospitalar: Processamento de Artigos e Superfícies em Estabelecimentos de Saúde. Brasília, 1994.

BRASIL. Ministério da Saúde. Coordenação de controle de Infecção Hospitalar: Processamento de Artigos e Superfícies em Estabelecimentos de Saúde. Brasília, 1994.

BRASIL. Ministério da Saúde. Portaria 321 de 26 de maio de 1988. Normas e os padrões mínimos, que com esta baixam, destinados a disciplinar a construção, instalação e o funcionamento de creches, em todo o território nacional. Brasília, 1988.

BRASIL. Ministério da Saúde. Resolução RDC n 216 de 15 de setembro de 2004.

Regulamento Técnico de Boas Práticas para Serviços de Alimentação. Acesso em: 05 out. 2018.

BRASIL. Ministério da Saúde. Surtos de Doenças Transmitidas por Alimentos no Brasil. Acesso em ago. 2018.

BRASIL. Presidência da República. Casa Civil. Decreto n ${ }^{\circ} 8552$ de 3 de novembro de 2015. Regulamenta a Lei $\mathrm{n}^{\mathrm{o}} 11265$, de 3 de janeiro de 2006. Comercialização de alimentos para lactentes e crianças de primeira infância e de produtos de puericultura correlatos. Disponível em: https:/ /www.planalto.gov.br/ ccivil_03/_ Ato2015-2018/2015/Decreto/D8552.htm. Acesso em: ago. 2018.

BRASIL. Secretaria da Saúde do Estado do Rio Grande do Sul. Portaria 172 de 03 de maio de 2005. Estabelece o regulamento técnico para licenciamento de Estabelecimentos de Educação Infantil. Porto Alegre, 2005. 
BRISSE, S. et al. Virulent clones of Klebsiella pneumoniae: identification and evolutionary scenario based on genomic and phenotypic characterization. PLoS One, v. 4, pp. 49-82, 2009.

BUCCINI G. S.; BENICIO M. H. D.; VENANCIO S. I. Determinantes do uso de chupeta e mamadeira. Rev Saúde Pública, v. 48, n. 4.

CARDOSO G. S; SANTANA A. D. C; AGUIAR C. P. Prevalência e aspectos epidemiológicos da giardíase em creches no município de Aracaju, SE, Brasil. Revista da Sociedade Brasileira de Medicina Tropical, n. 28, p. 25-31, 1995.

CHAPMAN, O. D. The Genus Klebsiella. Journal of Bacteriology, v. 51, n. 5, p. 637, 1946.

CORRÊA A. M. et al. Evolução da relação entre peso e altura e peso e idade em crianças de 3 meses a 6 anos assistidas em creches, Sorocaba (SP), Brasil. Rev Panam Salud Publica, v. 6, p. 26-33, 1999.

FERREIRA, E. N. W. A; COSTA, E. C. S. Manual de Vigilância à saúde em creches e pré-escolas. Campinas, 2001.

FISBERG R. M., MARCHIONI D. M. L., CARDOSO M. R. A. Estado nutricional e fatores associados ao déficit de crescimento de crianças frequentadoras de creches públicas do Município de São Paulo, Brasil. Cad. Saúde Pública, Rio de Janeiro, v. 20, n. 3, p. 812-817, mai-jun, 2004.

FONTANA, N. Atividade antimicrobiana de desinfetantes utilizados na sanitização de alface. 2006. 26 f. Trabalho de Conclusão de Curso - Curso de Nutrição, UNIFRA, Santa Maria, 2006.

FRANCO, B. G.; LANDGRAF, M. Microbiologia dos alimentos. São Paulo: Atheneu, 2002.

GALEGO, D. S; FUJIWARA, M. E. Y; FREITAS, P. V; BARRIOS, W. D. Manual de Lactários: Lactário nos estabelecimentos assistenciais de saúde e creches. São Paulo, 2017.

GENELAC. Grupo de Estudos em Nutrição Enteral e Lactário. Manual de Boas Práticas em Lactário. 2013.

GRANADA, G. G. et al. Vinagres de folha de videira: aspectos sensoriais. B. Ceppa. Curitiba, PR, v. 18, n.1, p.51-56, jan./jun.2000.

GURGEL, R.Q; et al. Creche: ambiente expositor ou protetor nas infestações pó parasitas intestinais em Aracajú, SE. Rev. Da Sociedade Brasileira de Medicina Tropical, mai/jun. 2005. 
HOLMSTRUP P.; SAMARANAYAKE, L. P. Acute and Aids related oral candidoses. In: Samaranayake L. P.; MAC FARLANE, T. W. Oral Candidoses. Cap. 8, p. 133-155, Londres, 1990.

HOPPE J. E. Treatment of orophanyngeal candidiasis in immunocompetent infants: a randomized multicenter study of miconazol gel vs. nystatin suspension. Pediatr Infect Dis J, v. 16, n.9, p. 288-293, 1997.

JONES, R. N. Microbial etiologies of hospital-acquired bacterial pneumonia and ventilator-associated bacterial pneumonia. Clinical Infectious Diseases, v. 51, S81S87, 2010.

NASCIMENTO, M. S. et al., Avaliação comparativa de diferentes desinfetantes na sanitização de uva. Brazilian Journal of Food Technology. v.6, n.1, p.6368, jan./ jun.2003.

NATARO J. P.; KAPER, J. Diarrheagenic Escherichia coli. Clinical Microbiology Reviews, v.11, p. 142-201, 1998.

NOGUEIRA, P., S., F. et al. Perfil da infecção hospitalar em um hospital universitário. Revista enfermagem UERJ, Rio de Janeiro, v. 17, n. 1, p. 96-101, Mar. 2009.

OLIVEIRA, A. M. et al. Manipuladores de alimentos: um fator de risco. Higiene Alimentar, v. 17, n. 12, p. 114-115, 2003.

OLIVEIRA, M. N; BRASIL. A. L. D; TADDEI, J. A. A. C. Avaliação das condições higiênico-sanitárias das cozinhas de creches públicas e filantrópicas. Ciênc. Saúde colet. v. 13, n. 3, p. 1051-1060, 2008.

PACZOSA, M. K.; MECSAS, J. Klebsiella pneumoniae: Going on the Offense with a Strong Defense. Microbiology and molecular Biology Review, v. 80. n 03. p. 629-661, 2016.

PERNA, T. D. G. S. et al. Prevalência de infecção hospitalar pela bactéria do genêro Klebsiella pneumoniae em Unidade de Terapia Intensiva. Revista da Sociedade Brasileira de Clínica Médica, v. 13, n² 2, p. 119-23, 2015.

SALLES R. K.; GOULART R. Diagnóstico das condições higiênico-sanitárias e microbiológicas de lactários hospitalares. Ver. Saude Publica, v. 31, n. 2, p. 131-139, abril de 1997.

SCAPARE, E. C.; COSSATIS, J. J. A presença de Klebsiella pneumoniae produtora de $\beta$-Lactamase de espectro estendido no ambiente hospitalar. Saúde \& Amb Rev., v. 4, n. 1, p. 1-11, 2009.

SCHERMA, A. P et al. Avaliação de fatores predisponentes à candidose bucal em recém-nascidos. Cienc Odontol Bras., v.7. n. 1, p. 52-57, jan-mar, 2004. 
SILVA JÚNIOR, E. A. Manual de Controle Higiênico Sanitário dos Alimentos. 4. ed. São Paulo: Varela, 2001.

SIQUEIRA J. R. J. F et al. Antibacterial effects of endodontic irrigants on blackpigmented gram-negative anaerobes and facultative bactéria. J. Endod., v. 24. n. 6, p. 414-416, jun. 1998.

SIVIEIRO A. A. et al. Intervenção e orientação nutricional no acompanhamento de crianças desnutridas em creches de São Paulo. Revista Paulista de Pediatria, v. 15, p. 7-13, 1997.

SOUSA, C.; P. Segurança alimentar e doenças veiculadas por alimentos: utilização do grupo coliforme como um dos indicadores de qualidade de alimentos. Revista APS, v. 9, n. 1, p. 83-88, jan/jun. 2006. 